\title{
And the award goes to...
}

\author{
The work of many plant biologists has garnered prizes and plaudits in recent months. But will we continue to see \\ plant researchers overlooked for the ultimate scientific awards?
}

$\mathrm{n}$ the entertainment industry, the early months of each year are 'Awards Season'. Starting with the Golden Globes in early January, continuing with ceremonies including the Grammys, Baftas and Brits, and culminating in the Oscars in early March. Scientists too, have their awards recognising outstanding achievements and it is good to see that this year quite a number of plant scientists have been honoured.

For instance, the Gruber prize for genetics has been awarded to Joanne Chory of the Salk Institute, and Elliot Meyerowitz of the California Institute of Technology. This prize is one of three awarded by the Yale University-based Gruber Foundation, each worth $\$ 500,000$, recognising excellence in cosmology, neuroscience and genetics. Chory and Meyerowitz are certainly worthy of such recognition, the difficulty being deciding which of their many achievements to single out. The Gruber foundation recognised Chory for her discovery and characterization of the hormonal signalling mechanisms central to plant growthregulation in response to light and other environmental signals, and Meyerowitz for pioneering the use of Arabidopsis thaliana in studying plant development.

Less lucrative than the Gruber (only $\$ 5,000$ ) is the Southeastern Universities Research Association Distinguished Scientist Award. As with the Gruber, 2018 is the first year in which this award has gone to a plant biologist: Pam Soltis of the University of Florida's Museum of Natural History. Soltis is a geneticist and systematician, using molecular techniques to investigate the phylogeny and evolution of plants. The award though, does not simply relate to her research but also her involvement last year in a multimedia arts project called One Tree, One Planet (https://go.nature. $\mathrm{com} / 2 \mathrm{kfZkHh}$ ), which aimed to increase public understanding of biodiversity.

Other examples of plant biologists gaining general scientific prizes is Wolf Frommer and Cyril Zipfel. Frommer, head of the Institute of Molecular Physiology at Heinrich Heine University, Dusseldorf, received the Tsungming Tu Award, Taiwan's highest academic honour for a foreign researcher, which commemorates the first Taiwanese scientist to receive a doctorate. Meanwhile, Zipfel has become the fourth recipient of the Tsuneko \& Reiji Okazaki Award, presented by Nagoya University in Japan. This commemorates the husband and wife team after whom the short discontinuous fragments of DNA that form during DNA replication on the lagging template strand (and so have to be joined by a DNA ligase to form a continuous strand) are named. The prize recognises the 'extraordinary efforts and accomplishments' of young scientists and so encourage their future success. Zipfel's successes in the field of plant immunity are already considerable and he is in the process of moving his group from the Sainsbury Laboratory in Norwich, UK, of which he has been Head for several years, to the University of Zurich to head its Molecular and Cellular Plant Physiology group.

Along with prizes, the start of the year is when new members are elected to a number of scientific societies. Of the 53 other new members of the European Molecular Biology Organisation (EMBO), there are three plant biologists. Zipfel, again, along with Eugenia Russinova, who works on brassinosteroid signalling at the Center for Plant Systems Biology at the Vlaams Instituut voor Biotechnologie (VIB), University of Ghent, Belgium, and Marja Timmermans, who investigates sRNA signalling and leaf development at the University of Tübingen.

In the UK, three plant biologists are among the 50 new Fellows of the Royal Society (FRS): Richard Dixon, of the Hagler Institute for Advanced Study at Texas A\&M University; and two researchers working in Norwich, UK, Cathie Martin and Sophien Kamoun. Both Dixon and Martin are known for their work on plant metabolism. Dixon's is concerned with secondary cell wall formation, especially in grasses, while Martin has most recently focussed on polyphenol production in fruits, leading to her engineering of 'purple' tomatoes high in antioxidant anthocyanins. Kamoun, like Zipfel, works on plant defence and was Zipfel's predecessor as Head of the Sainsbury Lab. He is also the first Tunisian scientist to be made an FRS, prompting the Tunisian Embassy in London to personally congratulate him on Facebook.

May also heralds new members of the National Academy of Sciences (NAS), USA.
In 2018 these include: Joy Bergelson from the University of Chicago, whose current research looks at microbial communities on plants; the University of California, Riverside's Sean Cutler, who employs genetics and chemical biology in the study and manipulation of drought tolerance; Susan McCouch of Cornell University, who studies natural variation in wild and cultivated rice; University of Minnesota ecophysiologist, Peter Reich, who investigates the effects of natural and human-related environmental change on forest ecosystems; and Richard Vierstra, whose studies at the University of Washington concentrate on signalling involving protein degradation. Finally, photosynthesis researcher Eva-Marie Aro, from the University of Turku, Finland, joins as a Foreign Member.

Also elected to the NAS this year is the University of Chicago economist, Richard Thaler. Thaler was awarded the Nobel Memorial Prize in Economic Sciences in 2017, which might suggest that joining the NAS is harder than winning a Nobel Prize. That is not the case for plant biologists, who are almost absent from the ranks of Nobel laureates. Barbara McClintock was awarded the Physiology or Medicine Nobel in 1983 for her discovery of transposable elements in maize, and remains the only woman to have won a science Nobel unshared. Other than her, Johann Deisenhofer, Robert Huber and Hartmut Michel were awarded the 1988 Chemistry prize for their determination of the structure of a photosynthetic reaction centre, but none would consider themselves plant biologists and the complex was from the purple bacterium Rhodopseudomonas viridis. Norman Borlaug received a Nobel for his work improving crop yields, but rather than a 'research' award he was given the 1970 Peace prize.

All plant biologists who have received recognition in this scientific awards season deserve hearty congratulation. It is to be hoped that these may soon result in more plant biologists receiving long overdue invitations to Sweden.

Published online: 5 June 2018 https://doi.org/10.1038/s41477-018-0186-X 